\title{
The Effects of Epinephrine Infusion in Patients with Von Willebrand's Disease
}

\author{
Frederick R. Rickies, Leon W. Hoyer, Margaret E. Rick, and \\ DAvid J. AHR with the technical assistance of JEANNIE ChIn \\ From the Department of Hematology, Walter Reed Army Institute of Research, \\ Walter Reed Army Medical Center, Washington, D. C. 20012, the Department \\ of Medicine, University of Connecticut School of Medicine, Farmington, \\ Connecticut 06032, and the Medical Service, Veterans Administration Hospital, \\ Newington, Connecticut 06111
}

\begin{abstract}
A B S T R A C T Epinephrine infusion causes variable increases in the components of the Factor VIII (antihemophilic factor) complex in patients with von Willebrand's disease. The increase in antihemophilic factor procoagulant activity was greater than that of Factor VIII-related antigen and von Willebrand factor activity in two patients with von Willebrand's disease. Similar increases in the three individual factors were demonstrated in two other patients. A 4-10-fold increase in Factor VIII-related properties was identified in each of these individuals after infusion. One patient has been studied with very severe von Willebrand's disease; none of the Factor VIII-related properties increased despite two infusions of epinephrine. Bleeding times were normalized or remained normal in the two patients whose von Willebrand factor activity was greater than $25 \mathrm{U} /$ $100 \mathrm{ml}$. It remained prolonged in those three patients whose von Willebrand factor activity levels remained below that concentration. The increase in procoagulant activity was transient in all patients and $t \frac{1}{2}$ values were estimated to be between 0.8 and $3.4 \mathrm{~h}$.
\end{abstract}

\section{INTRODUCTION}

Most patients with von Willebrand's disease (VWD) ${ }^{1}$ have reduced plasma levels of antihemophilic factor pro-

This work was presented in part at the 17th Annual Meeting of the American Society of Hematology, Atlanta, Ga., 1 December, 1974, and appeared in abstract form in Blood. 44 : 907.1974.

Received for publication 27 September 1975 and in revised form 27 January 1976.

${ }^{1}$ Abbreviations used in this paper: Factor VIII (antihemophilic factor, AHF), general term for the plasma protein; VIII $_{\triangle \mathrm{GN}}$, antigen which precipitates with rabbit antibody prepared against human factor VIII; VIII $I_{\mathbf{A H F}}$. clot- coagulant activity (VIII $\mathrm{VHF}_{\mathbf{A F}}$ ), antihemophilic factor antigen (VIII $\left.I_{\triangle G N}\right)$, and von Willebrand factor activity (VIIIVwF) (1). In addition, patients with VWD generally manifest abnormal bleeding times, diminished retention of their platelets to glass bead filters, and a characteristic delayed response to transfusion with plasma or antihemophilic factor (Factor VIII) concentrates (2-7).

Although it has both practical and conceptual importance, the cause of the sustained rise in VIII $\mathrm{VIF}_{\mathbf{B}}$ after transfusion in VWD, greater than that calculated from the quantity of VIII $\mathrm{VHF}_{\mathbf{A}}$ transfused, is not understood (4-7). Previous studies have suggested that this posttransfusion VIII $_{\triangle \mathrm{HF}}$ has physicochemical (8) and procoagulant (4-7) properties like those of normal plasma Factor VIII. While susceptible to inactivation by both human and rabbit anti-Factor VIII antibodies (9), it has been reported that the "stimulated Factor VIII" does not precipitate with rabbit anti-Factor VIII $(9,10)$, an observation which suggests an incomplete Factor VIII may be produced in these patients. Studies in our laboratory (11) and elsewhere $(10,12,13)$, have shown variable responses after transfusion of plasma or cryoprecipitate in these patients, however; these differences may reflect differences in the nature or quantity of infused materials or, perhaps, inherent variability among patients with VWD.

VIII $_{\mathrm{ABF}}$ rises in response to a variety of acute and chronic stimuli in patients who do not have VWD (14-

promoting activity of factor VIII; VIII factor, identified in plasma as the activity which supports the aggregation of washed platelets by ristocetin (1); VWD, von Willebrand's disease. 
26). A proportional increase in VIII $\mathrm{VIN}_{\triangle \mathrm{N}}$ has usually been identified (21-24), although discrepancies have been noted in liver disease $(25,26)$, renal disease associated with uremia and myocardial infarction (26), where disproportionately high levels of VIII $\mathrm{V}_{\mathrm{AgN}}$ have been demonstrated in some, but not all, cases. VIII ${ }_{\mathrm{AHF}}$ rises in patients with VWD in response to exercise or adrenaline, (15-17), as it does in normal individuals (14-16, 18-24), but there is no information regarding VIII ${ }_{A G N}$ or VIIIvw in these patients.

We report here studies of VIII $_{\triangle \mathrm{AFF}}, \mathrm{VIII}_{\triangle \mathrm{GN}}$, and VIIIrw in patients with VWD given infusions of epinephrine hydrochloride in an attempt to characterize the "stimulated AHF" under conditions which are not complicated by the presence of exogenous plasma proteins. They demonstrated that epinephrine induces a

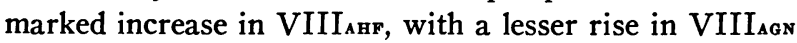
and VIIIvwr in some patients with mild and moderate VWD; no response was detected in severe VWD.

\section{METHODS}

Patients with known VWD and normal cardiovascular and renal function were hospitalized on the Lawrence Kyle metabolic ward of the Walter Reed Army Medical Center or at the University of Connecticut Health Center. Complete bed rest was enforced during the study and patients were prohibited from smoking, ingesting coffee, tea, cocoa, or other caffeinated beverages. All patients were instructed to avoid the use of oral contraceptive agents, corticosteroids, or other agents known to affect VIII ${ }_{A H F}$ levels (7). Informed consent was obtained from all patients and the protocol was approved by the human experimentation committees of both medical centers.

Patients were sedated with $100 \mathrm{mg}$ of secobarbital the evening before the study. All blood samples were obtained with the patients in the supine position utilizing a no. 19 gauge scalp vein needle and polypropylene syringe. A slow infusion of $5 \%$ dextrose in water was maintained through the needle to keep it patent and $7 \mathrm{ml}$ of blood-glucose solution was discarded before drawing each specimen.

Epinephrine hydrochloride (Parke, Davis and Co., Detroit, Mich.) in $23.4-77 \mathrm{ml}$ of $0.9 \%$ saline, a total dose of $0.0042 \mathrm{mg} / \mathrm{kg}$, was infused at a constant rate by infusion pump (Harvard Apparatus Co., Inc., Millis, Mass.) over $30 \mathrm{~min}$. A mean pulse rate increase of 33 beats $/ \mathrm{min}$ was observed and systolic pressure increased $38 \mathrm{~mm} \mathrm{Hg}$. Cardiac rhythm was monitored throughout the experiment and symptoms were limited to mild anxiety, palpitations, and peripheral vasoconstriction. A brief period of atrial-ventricular dissociation was noted in one patient (H. E.) but disappeared immediately upon discontinuation of the infusion. No other dysrhythmias were noted.

Blood was collected into a buffered citrate solution containing $0.1 \mathrm{M}$ sodium citrate (three parts) and $0.1 \mathrm{M}$ citric acid (two parts) with a $\mathrm{pH}$ of 5.1 (nine parts blood: one part anticoagulant) in polypropylene tubes (Falcon Plastics, Oxnard, Calif.) and immediately centrifuged $(12,500 \mathrm{~g})$ at $4^{\circ} \mathrm{C}$ for $20 \mathrm{~min}$. Citrated plasma was assayed immediately for VIII $\mathrm{VHF}_{\mathrm{AH}}$ by a modification of the one stage activated partial thromboplastin time assay (27) utilizing Platelin-PlusActivator (General Diagnostics, Morris Plains, N. J.) and naturally deficient substrate on a Clot-Tek clot timer ( $\mathrm{Hy}$ land Div., Travenol Laboratories, Inc., Costa Mesa, Calif.) as previously described (28). Sample plasmas for other assays were frozen immediately in dry ice and acetone and stored at $-70^{\circ} \mathrm{C}$. VIII ${ }_{A G N}$ and VIII VwF $_{\text {were determined on }}$ frozen samples by radioimmunoassay (29) and the washed platelet-ristocetin (Abbott Laboratories, North Chicago, III.) assay (1). Bleeding times were determined by the method of Mielke et al. (30); the normal range in our laboratory is 2-6 min. Plasma samples containing the postinfusion peak VIII $_{A H F}$ levels were chromatographed on $6 \%$ agarose (Bio-Gel A5M, Bio-Rad Laboratories, Richmond, Calif.) using a $1.6 \times 28-\mathrm{cm}$ column (Pharmacia Fine Chemicals, Inc., Piscataway, N. J.) at an elution rate of $20 \mathrm{ml} / \mathrm{h}$. $2-\mathrm{ml}$ fractions were collected using barbital-saline $(7.3 \mathrm{~g}$ $\mathrm{NaCl}, 2.76 \mathrm{~g}$ barbital, $2.06 \mathrm{~g} \mathrm{Na}$ barbital/liter, $\mathrm{pH}$ 6.8) as the eluting buffer. VIII $_{\triangle H F}$ in column fractions was determined by the method of Breckenridge and Ratnoff (31). All assays of the Factor VIII properties (VIII $_{\triangle H F}$, VIII ${ }_{\triangle G N}$, VIII $_{\text {vwr }}$ ) are expressed as units $/ 100 \mathrm{ml}$. A frozen pool prepared from plasmas from 20 individuals with no history of bleeding disorders was used as standard in these studies and is designated as having $100 \mathrm{U} / 100 \mathrm{ml}$ of each property.

The sucrose density gradient methods have been described (32). Briefly, $13.5 \mathrm{ml}$ continuous $10-40 \%$ sucrose density gradients were prepared in imidazole-saline $(0.02 \mathrm{M}$ imidazole, $0.14 \mathrm{M} \mathrm{NaCl}, \mathrm{pH} \mathrm{7.4})$. Whole plasma $(0.75 \mathrm{ml})$ was applied to gradients which were centrifuged for $27 \mathrm{~h}$ at $201,800 \mathrm{~g}$ at $4^{\circ} \mathrm{C}$ using an SW 40 head. Recovery of VIII $\mathrm{VHF}_{\Delta \mathrm{F}}$ and VIII $_{A G N}$ exceeded $75 \%$. Samples were assayed for VIII $_{\triangle \mathrm{BF}}$ at 1:6 dilutions or greater (32).

\section{RESULTS}

Table I summarizes the clinical and laboratory features of the five patients who have been studied. One patient (W. H.) had mild clinical bleeding with only a modest increase in bleeding after surgical challenge. Three (D. K., M. H., and C. P.) had evidence of moderate clinical bleeding (epistaxis, menometrorrhagia, and transfusions after minor surgical procedures) and one (H. E.) had clinically severe bleeding (spontaneous hemarthroses). Except in H. E., the severity of the bleeding disorder did not correlate well with the levels of the several components of the Factor VIII complex.

The response to epinephrine infusion was similar in patients W. H. (Fig. 1) and D. K. (Fig. 2). An im-

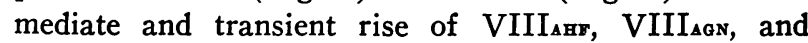
VIIIrwy was noted and the peak values of each were approximately four times the basal levels. The three values fell rapidly after the epinephrine infusion was discontinued. The estimated $t \frac{1}{2}$ values for VIII $_{A B F}$ were $3.1 \mathrm{~h}$ (W. H.) and $1.6 \mathrm{~h}$ (D. K.). The bleeding time became normal in patient $\mathrm{D} . \mathrm{K}$. for approximately $1 \mathrm{~h}$, the greatest shortening, to $4 \mathrm{~min}$, being noted immediately after the epinephrine infusion. The bleeding time remained greater than $20 \mathrm{~min}$ in patient $\mathrm{W} . \mathrm{H}$.

Somewhat greater increase in VIII $_{\triangle B F}$ than in VIII VGN or VIIIVwF was noted after epinephrine infusion in patients M. H. (Fig. 3) and C. P. (Fig. 4), both of whom

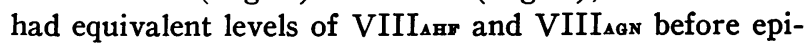


TABLE I

VWD Patients

\begin{tabular}{|c|c|c|c|c|c|c|}
\hline Patient & Age: Sex & VIIIIAHF $_{A}$ & VIII $_{A G N}$ & VIIIvwF & $\begin{array}{l}\text { Bleeding } \\
\text { time }\end{array}$ & Severity of clinical disease \\
\hline & & $U / 100 \mathrm{ml}$ & $U / 100 \mathrm{ml}$ & $\mathrm{U} / 100 \mathrm{ml}$ & $(\min )$ & \\
\hline W. H. & 27: Male & 23 & 6 & 5 & $>20$ & Mild (bleeding after tooth extraction). \\
\hline D. K. & 27:Female & 30 & 8 & $<5$ & 10 & $\begin{array}{l}\text { Moderate (Menometrorrhagia; bleeding } \\
\text { after tooth extraction requiring } \\
\text { transfusion). }\end{array}$ \\
\hline M. H. & $41:$ Female & 47 & 30 & 43 & 6 & $\begin{array}{l}\text { Moderate (Bleeding requiring transfusion } \\
\text { after minor surgery; epistaxis). }\end{array}$ \\
\hline C. P. & $26:$ Female & 8 & 8 & $<10$ & $>20$ & Moderate (Intense menometrorrhagia). \\
\hline H. E. & 41: Male & $<1$ & $<1$ & $<10$ & $>20$ & Severe (Spontaneous hemarthroses, etc.). \\
\hline Normal range & & 50-155 & $60-168$ & $55-130$ & $2-6$ & \\
\hline
\end{tabular}

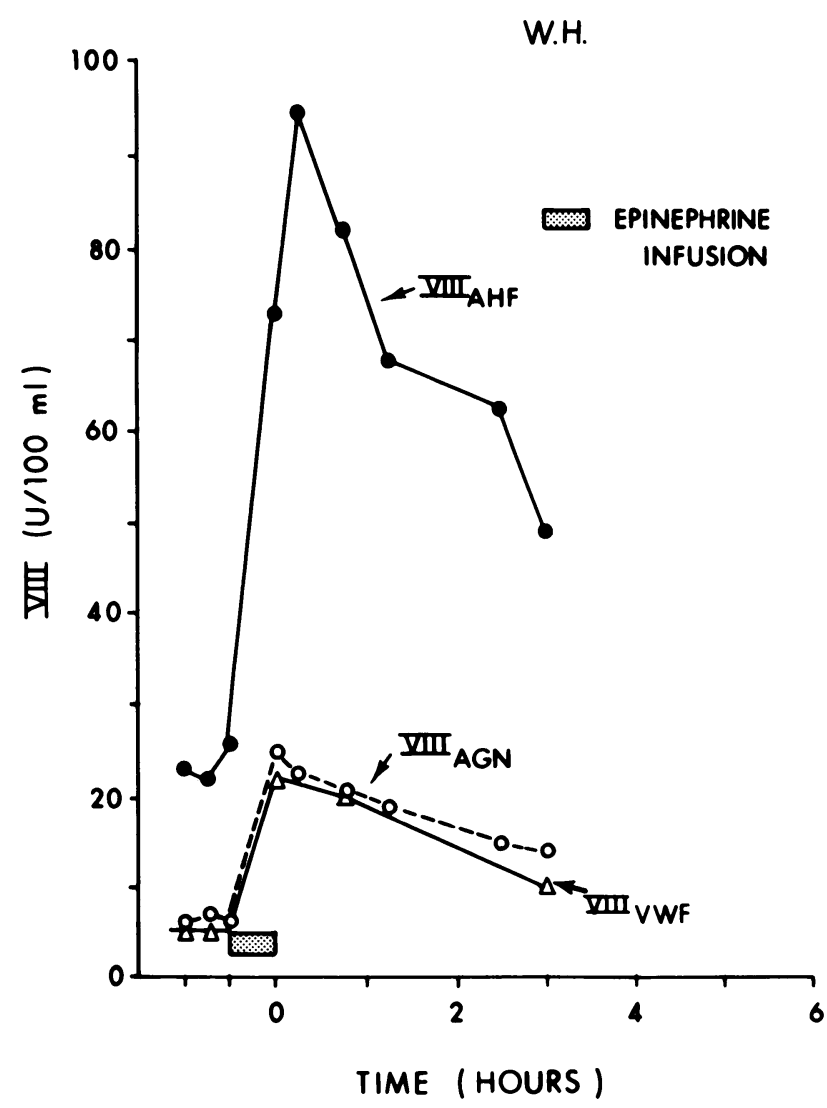

FIGURE 1 Antihemophilic factor (Factor VIII) procoagu-

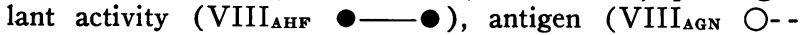
- -O), and von Willebrand factor activity (VIII $\mathrm{VwF} \triangle-$ $-\triangle)$ after epinephrine infusion in patient W. H. The plasma levels of each of these three properties are indicated on the vertical axis. Pooled normal plasma $(100 \mathrm{U} / 100 \mathrm{ml})$ is the standard for each assay. Three "base-line" plasma samples were obtained with the intravenous needle in place before infusion of epinephrine. The bleeding time was recorded as $>20$ min before the infusion, immediately after the infusion and 45 min later. nephrine infusion. C. P. (Fig. 4) had an immediate 10fold rise of VIII $_{\triangle H F}$ but minimal response of VIII $\triangle$ AN or VIIIrwr. Although all Factor VIII-related measures rose after epinephrine infusion in $M$. $H$., the magnitude of the VIII $\triangle \mathrm{ABF}$ increase (ninefold; from 45 to $400 \mathrm{U} / 100$ $\mathrm{ml}$ ) and the VIII $\mathrm{vwF}_{\mathrm{w}}$ increase (eightfold; from 32 to $256 \mathrm{U} / 100 \mathrm{ml}$ ) was greater than that for VIII $\triangle \mathrm{AGN}$ (fourfold; from 35 to $138 \mathrm{U} / 100 \mathrm{ml}$ ). The duration of VIII $\mathrm{AHF}_{\mathrm{AB}}$ elevation in these two patients was also brief; estimated $\mathrm{t}_{\frac{1}{2}}$ values were $3.4 \mathrm{~h}$ in $\mathrm{M}$. $\mathrm{H}$. and 0.8 hours in $\mathrm{C}$. $\mathrm{P}$. The bleeding time was normal before epinephrine infusion in

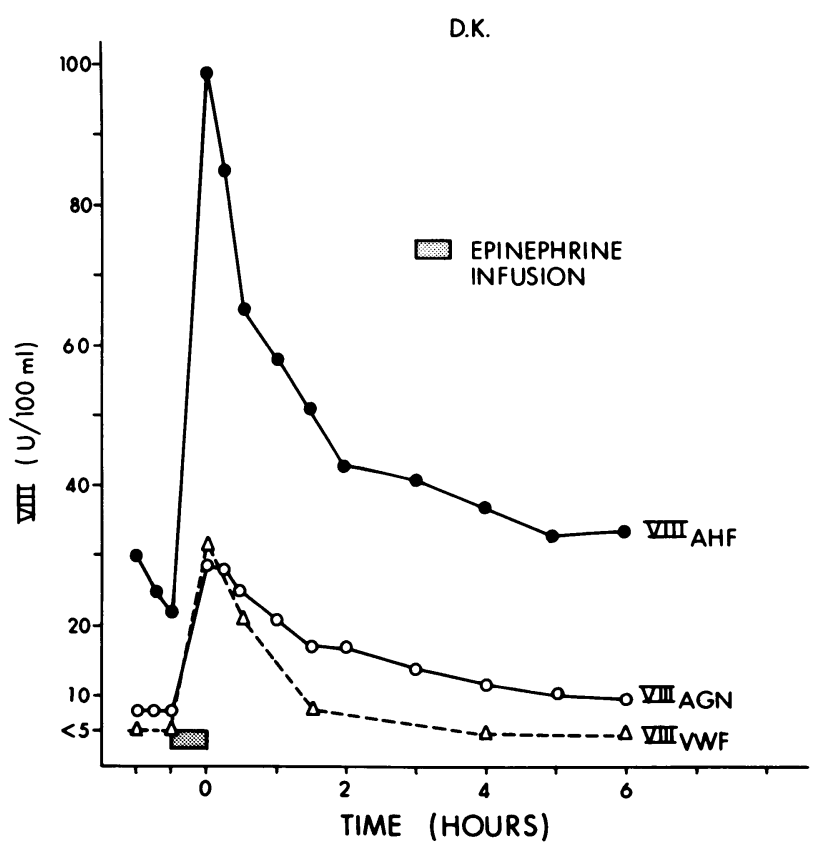

FIGURE $2 \operatorname{VIII}_{\triangle \mathrm{AHF}}(\bullet-\bullet), \operatorname{VIII}_{\mathrm{AGN}}(\mathrm{O}-\mathrm{O})$, and VIII $_{\mathrm{VWF}}(\triangle---\Delta)$ after epinephrine infusion in patient D. K. The bleeding time was $10 \mathrm{~min}$ before the infusion $(\mathrm{N}=2-6), 4 \frac{1}{2} \mathrm{~min}$ immediately after the infusion, $4 \mathrm{~min}$ at $15 \mathrm{~min}$ postinfusion, $17 \mathrm{~min}$ at $1 \mathrm{~h}$, and $>20 \mathrm{~min}$ at $2 \mathrm{~h}$ postinfusion. 
M.H.

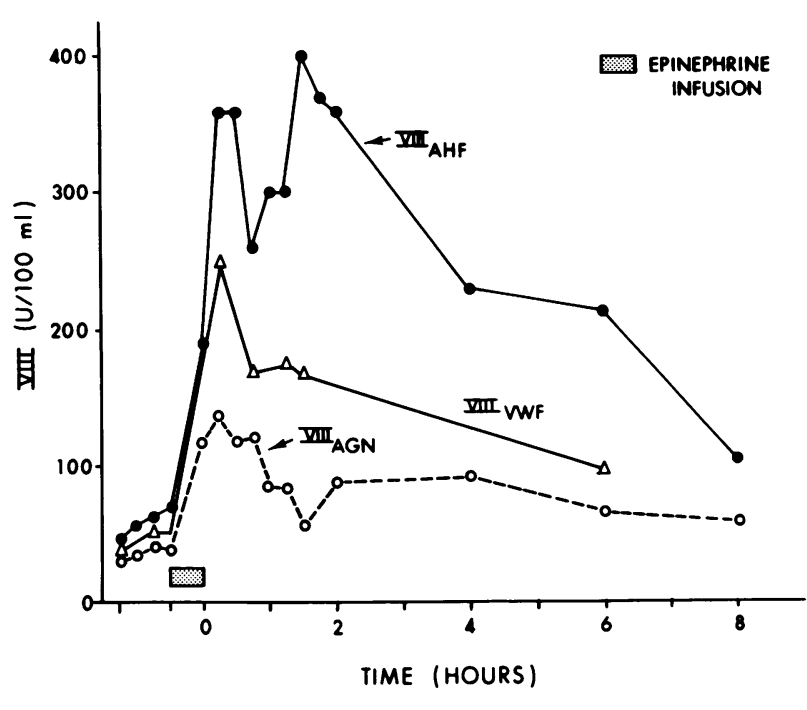

FIGURE $3 \operatorname{VIII}_{\Delta \mathrm{HF}}(\bullet-\bullet), \operatorname{VIII}_{\mathrm{AGN}}\left(\mathrm{O}-\mathrm{C}_{-}\right)$, and VIII $_{\text {VwF }}(\triangle-\triangle)$ after epinephrine infusion in patient M. $H$. The bleeding time was 2 min before infusion and was unchanged immediately after infusion.

M. H. and no other determinations were carried out. The bleeding time remained longer than $20 \mathrm{~min}$ in C. P.

Patient H. E. (Fig. 5), whose VIII $\triangle$ GN level was less than $1 \mathrm{U} / 100 \mathrm{ml}$, was the most severely affected patient tested. No changes in VIII $\mathrm{VHF}_{\triangle \mathrm{HF}} \mathrm{VIII}_{\triangle \mathrm{AGN}}$, or VIII vwF could be detected after two separate epinephrine infusions and the bleeding time remained long (greater than $20 \mathrm{~min}$ ).

An estimate of the molecular size of the "stimulated VIII $_{\mathbf{A H F}}$ " was obtained by agarose gel chromatography and sucrose density gradient ultracentrifugation of plasma samples stored at $-70^{\circ} \mathrm{C}$ for $2-8 \mathrm{wk}$. Fig. 6 illustrates the chromatographic patterns found on the peak postepinephrine infusion samples of patients $\mathrm{W}$. $\mathrm{H}$. and

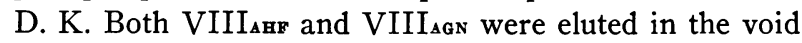
volume fractions indicating a molecular weight of greater than $1.0 \times 10^{\circ}$ daltons. This elution pattern is the same as that previously reported for normal plasma VIII $\mathrm{ABF}_{\mathrm{BF}}$ (33). A preliminary sucrose density centrifugation study has also been carried out with a postepinephrine infusion sample of patient D. K. The "stimulated VIII AHF" was found in the same fractions as VIII $_{\triangle \mathrm{BF}}$ in normal plasma, i.e. fractions which correspond to molecular weight of greater than $1.0 \times 10^{\circ}(32)$.

\section{DISCUSSION}

The response to transfusion of patients with VWD has intrigued observers since the initial description by Nilsson and co-workers in 1959 (4). Despite variability in response to transfused plasma among some patients with VWD (34), and a degree of overlap with normal individuals (35), the delayed peak and slower disap-

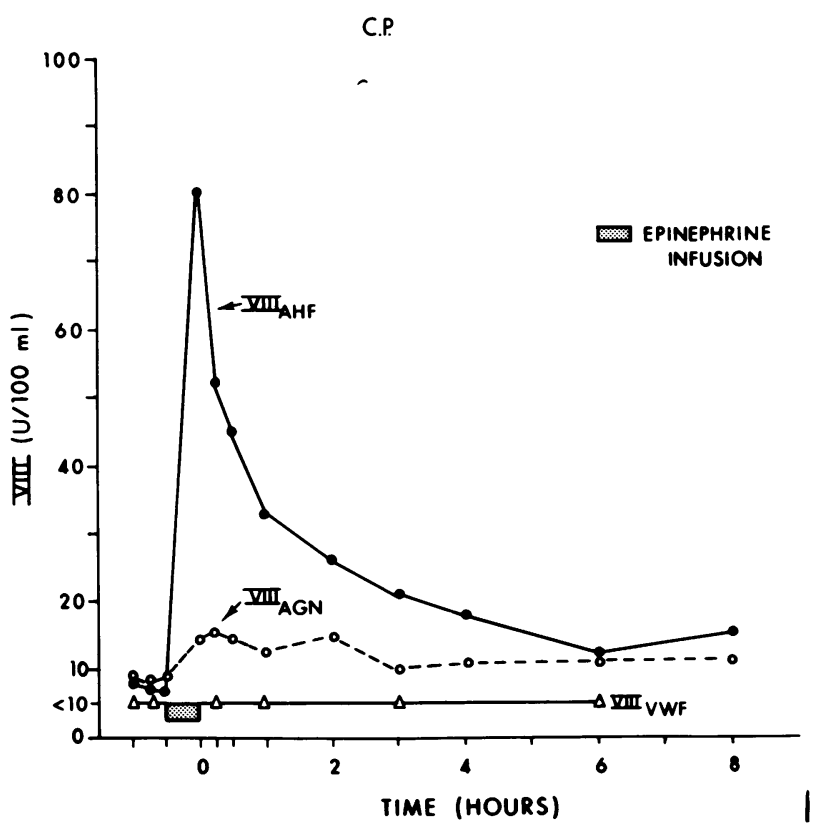

FIGURE 4 VIII $_{A H F}(\bullet-\bullet), \operatorname{VIII}_{\mathrm{AGN}}\left(\mathrm{O}_{---O}\right)$, and VIII $v$ FF $(\triangle-\triangle)$ after epinephrine infusion in patient C. $P$. The bleeding time was $>20$ min before infusion and remained $>20 \mathrm{~min}$ at $15 \mathrm{~min}, 30 \mathrm{~min}, 1 \mathrm{~h}$, and $2 \mathrm{~h}$ after the infusion.

pearance of VIII $\mathrm{VHF}_{\mathrm{AF}}$ after plasma transfusion has been considered characteristic of this disease (4-6). The control mechanisms of this response, however, and the nature of the "stimulated VIII ${ }_{\triangle B F}$ " remain uncertain. Although Barrow and colleagues did not detect physicochemical differences between normal VIII ${ }_{\mathbf{A B F}}$ and "stimulated VIII $\mathrm{AHF}_{\mathrm{AH}}$ " from a patient with VWD (8), recent studies have described rather marked in vitro lability of $\mathrm{VIII}_{\mathbf{A B F}}$ when VWD plasmas are stored for short periods at $-20^{\circ} \mathrm{C}(10,36)$. Additionally, immunochemical methods have demonstrated that plasmas with "stim-

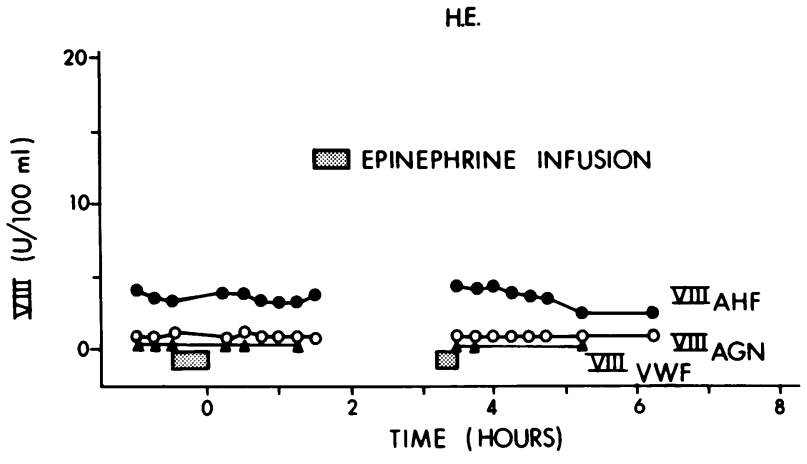

FigURE $5 \operatorname{VIII}_{\triangle \mathrm{AHF}}(\bullet-\bullet)$, $\operatorname{VIII}_{\triangle \mathrm{AGN}}(\mathrm{O}-\mathrm{O})$, and VIII H. E. The bleeding time was $>20$ min before the infusion and remained $>20$ min immediately after the infusion, and at $3 \mathrm{~h}$ after the infusion. 


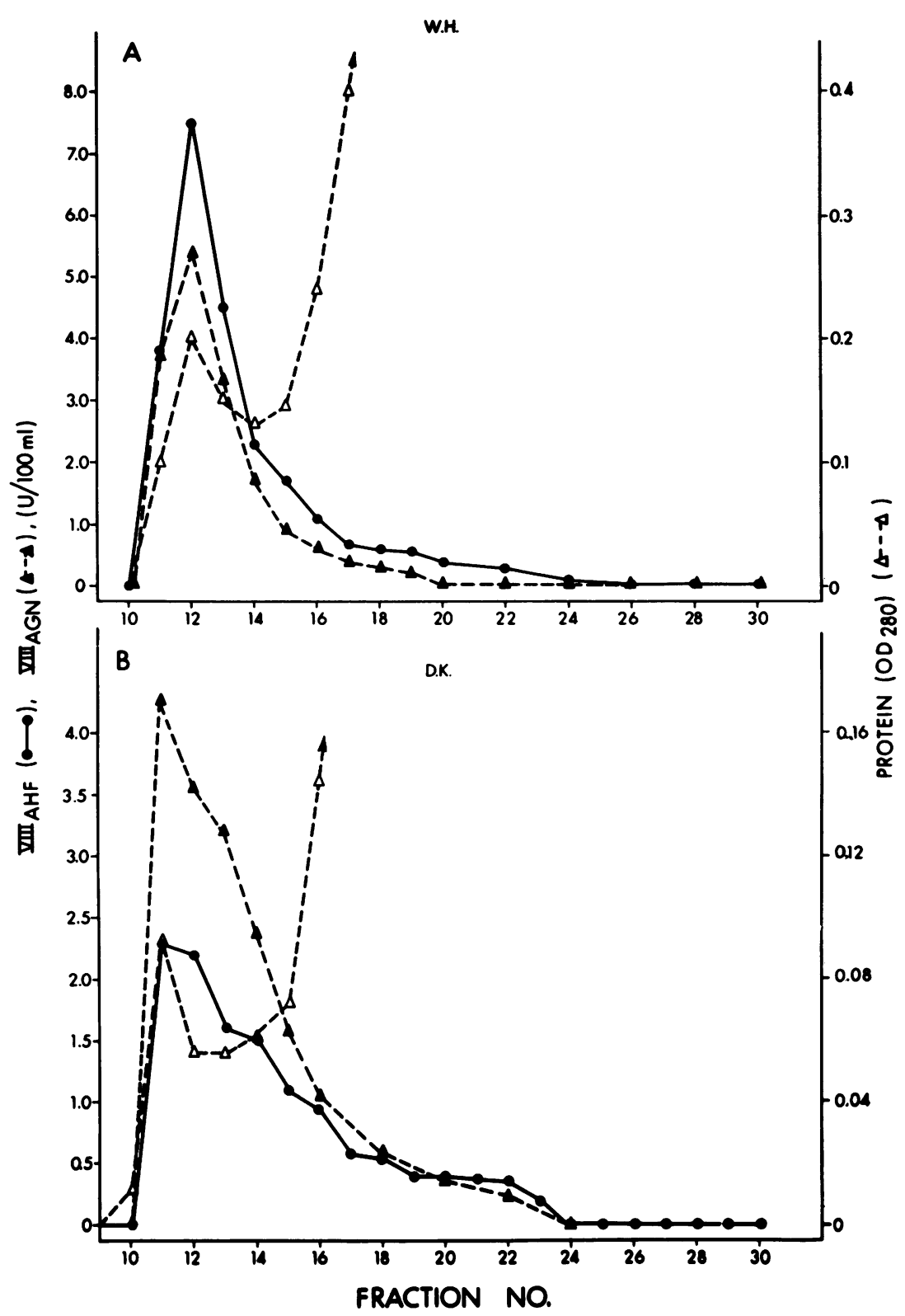

FIGURE 6 Chromatographic pattern of the peak postepinephrine infusion samples of patients

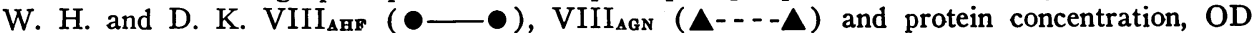
$280(\triangle--\triangle \Delta)$ are indicated on the vertical axes. Fraction numbers are plotted on the horizontal axis ( $2 \mathrm{ml}$ fractions). $2 \mathrm{ml}$ of plasma from W. $\mathrm{H}$. (containing $52 \mathrm{U}$ of $\mathrm{VIII}_{\triangle \mathrm{HF}} / 100 \mathrm{ml}$ ) and $1.4 \mathrm{ml}$ of plasma from $\mathrm{D}$. $\mathrm{K}$. (containing $96 \mathrm{U}$ of $\mathrm{VIII}_{\Delta \mathrm{HF}} / 100 \mathrm{ml}$ ) were applied to the agarose columns.

ulated VIII $_{\triangle \mathrm{AF}}$ " do not have corresponding levels of VIII $_{\text {AGN }}$ when measured by immunoprecipitation methods using rabbit antibodies $(9,10)$. These observations have led to the suggestion that the "stimulated VIII $\mathrm{VHF}_{\Delta \mathrm{BF}}$ " is indeed different from normal plasma VIII $_{A H F}$. Transfusion experiments are difficult to interpret, however, because of the variable responses to different therapeutic materials (37) and the possible effects of plasma proteins other than factor VIII.

Previous studies have identified an increase in Factor VIII procoagulant activity $\left(\mathrm{VIII}_{\Delta \mathrm{Bz}}\right)$ in VWD patients given epinephrine $(15,16)$, a rise which is more rapid and transient than that which follows plasma transfusion (4-6). We have confirmed the rapid response 
to epinephrine in this disease and have also identified an increase in VIII ${ }_{\triangle G N}$ and VIIIvwr. The rapid increase of all three properties after epinephrine infusion suggests that epinephrine stimulates the release of preformed Factor VIII rather than new synthesis. Moreover, it is clear that no exogenous protein intermediate is required for the release of VIII VHF, VIII $_{\triangle \mathrm{GN}}$, or VIIIvwF. The identification of VIII $\triangle$ GN in endothelial cells by immunofluorescence $(38,39)$, and the detection of both VIII $\triangle$ GN and VIIIvwr in the media of cultured human endothelial cells $(40,41)$, suggests that the rapid effect of epinephrine may be due to Factor VIII release from endothelial cells. This interpretation is supported by the identification of VIII $_{\text {AGN }}$ in endothelial cells of superficial veins obtained by biopsy in patients with mild or moderate VWD (42). The failure to detect an epinephrine effect in patient $\mathrm{H}$. E. is also consistent with this hypothesis, for VIII $\mathrm{VIGN}$ was not detected in endothelial cells of patients with severe VWD (42). Based on these studies, it is conceivable that pharmacologic manipulation of Factor VIII release may be accomplished in the future without supplying exogenous plasma proteins. Long acting vasoactive drugs may be useful in the support of patients with VWD during short term surgical procedures or in the management of limited trauma. Further investigation of the mechanism of the in vivo response of Factor VIII to pharmacologic agents seems warranted.

The bleeding time remained prolonged in two of the patients studied (W. H. and C. P.) even though VIII $_{\Delta \mathrm{Ar}}$, VIII $_{\Delta \mathrm{GN}}$, and VIIIVWr levels were increased after epinephrine infusion. Previous studies of the relationship of the bleeding time to VIIIrws suggest that a normal bleeding time indicates VIIIvwr levels above a critical value estimated to be between 20 and $40 \mathrm{U} / 100$ $\mathrm{ml}(1,43)$. The VIII ${ }_{\mathrm{rWF}}$ (and $\mathrm{VIII}_{\triangle \mathrm{GN}}$ ) levels remained below $25 \mathrm{U} / 100 \mathrm{ml}$ during the postinfusion period in both W. H. and C. P.; the persistently prolonged bleeding time in these patients is consistent with previous studies of this relationship $(1,43)$. In contrast, the bleeding time shortened from 10 to $4 \mathrm{~min}$ after epinephrine infusion in $\mathrm{D} . \mathrm{K}$. as the VIIIrwr level rose to 32 $\mathrm{U} / 100 \mathrm{ml}$. The correlation of bleeding time correction and VIIIvw levels in $\mathrm{D}$. $\mathrm{K}$. differs from the findings reported by Ratnoff and co-workers for two patients with VWD. In each of these individuals the bleeding time remained long even though VIII $_{\triangle \mathrm{HF}}$ and VIII $\mathrm{IGN}_{\triangle \mathrm{N}}$ rose to normal levels and the platelets aggregated normally with ristocetin $(44,45)$. These contrasting observations indicate the need for further careful studies of the relationship of the bleeding time and VIIIvwr levels in VWD.

The apparent in vivo difference in the VIII $\mathrm{IAF}_{\mathbf{A B}}$ response from that of the VIII $_{\triangle G N}$ and VIIIVwF in patient C. P. (Fig. 4) must be interpreted with caution. Al- though it is possible that epinephrine has a differential stimulatory effect on three separate entities, the nature of these assays makes it impossible to compare the different components of the Factor VIII complex in any direct way. Each property is quantified by reference to a normal plasma pool standard and only relative concentrations can be measured. If the normal plasma standard contains different numbers of molecules of the components of the Factor VIII complex, addition of material which has the same number of molecules of each component would cause variable changes in the values measured in the three assays. The different responses of the three properties would be most apparent if only a small proportion of the Factor VIII complexes in normal plasma had VIII $_{\Delta \mathrm{HF}}$ activity. If this were the case, the postinfusion changes in VIII $\mathrm{VHF}_{\mathbf{A B}}$ would be more striking if fully active molecules were released from endothelial cells by epinephrine stimulation. A similar differential response of VIII $_{\triangle A F}$ and VIII ${ }_{A G N}$ has been reported by Ruggeri and co-workers in their studies of a synthetic analogue of vasopressin. The basis for this differential response in plasma assay values was not discussed in their preliminary report (46).

We do not know how epinephrine causes changes in Factor VIII levels. Although this drug may effect the release of Factor VIII storage from sites, it is also possible that it may affect the Factor VIII molecule, either directly or indirectly. Transient thrombin generation, for example, would increase VIII $_{A B F}$ without affecting VIII $_{\Delta G N}$ or VIII $v w r$, i.e., VIII $\triangle$

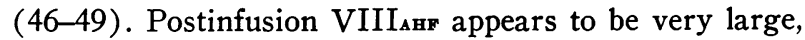
however, (Fig. 6), an observation which is not consistent with the changes in the sedimentation and chromatographic properties which have been described for thrombin-activated Factor VIII $(50,51)$. Further assessment of the possible role of thrombin generation during epinephrine infusion and of the properties of the "stimulated AHF" are in progress.

The pattern of Factor VIII related measurements after epinephrine infusion in C. P. (Fig. 4), normal VIII $_{\triangle H F}$ with very low VIII to that which has been identified after plasma or cryoprecipitate infusion in VWF $(9,10)$. Material which

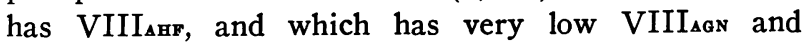
VIIIrwF levels, has also been identified in in vitro studies in which Factor VIII is exposed to high ionic strength buffers $(32,47)$. Although this similarity is of great interest, its significance is uncertain. Since VIII $\mathrm{AHF}$ obtained in high salt separations appears to have a lower molecular weight than the other components of the Factor VIII complex, we have examined the properties of

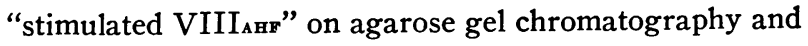
sucrose density gradient centrifugation. Although we have not identified any low molecular weight VIII $_{\triangle \mathrm{ABF}}$ in 
these studies, it is important to recognized the inherent problems in determining VIII $_{\triangle \mathrm{HF}}$ size. It is possible that the properties of postinfusion VIII $_{\triangle \mathrm{BF}}$ are modified by the association of low molecular weight material with the larger components of the factor VIII complex which are present in these plasmas. It is also possible that there is aggregation of "stimulated $\mathrm{VIII}_{\mathbf{A B F}}$ " during storage and/or in vitro analysis.

The different patterns of response to epinephrine in these patients may correspond to differences in the molecular defects which are responsible for VWD. In the most severe form of the disease (patient H. E.), no Factor VIII could be detected, even after epinephrine stimulation; this may represent an absolute defect in synthesis. Reduced but measurable quantities of the components of the Factor VIII complex are present in patients with mild and moderate VWD. The increases detected after epinephrine stimulation suggest that some control mechanisms are present in these individuals, however, and that they are susceptible to pharmacologic modification. The relationship of this modification to possible treatment of VWD remains to be determined.

\section{ACKNOWLEDGMENTS}

The authors wish to thank Mrs. Carol Church, Miss Norma Trabold, Mr. Carl Carta, and Mr. Charles Barr for excellent technical assistance. We thank Dr. Robert T. Breckenridge for referring patient $\mathrm{H}$. E. for study.

These studies were supported in part by grants HL 16626 and HL 16872 from the National Heart and Lung Institute. They represent part of the Veterans Administration project Medical Research Information System No. 7446-01.

\section{REFERENCES}

1. Weiss, H. J., L. W. Hoyer, F. R. Rickles, A. Varma, and J. Rogers. 1973. Quantitative assay of a plasma factor deficient in von Willebrand's disease that is necessary for platelet aggregation. Relationship to factor VIII procoagulant activity and antigen content. $J$. Clin. Invest. 52: 2708-2716.

2. von Willebrand, E. A. 1926. Hereditar pseudohemofili. Finsk. Lakaresallsk Handl. 68: 87-112.

3. Salzmann, E. W. 1963. Measurement of platelet adhesiveness. A simple in vitro technique demonstrating an abnormality in von Willebrand's disease. J. Lab. Clin. Med. 62: 724-735.

4. Nilsson, I. M., M. Blombäck, and B. Blombäck. 1959. von Willebrand's disease in Sweden. Its pathogenesis and treatment. Acta. Med. Scand. $164:$ 263-278.

5. Biggs, R., and J. M. Mathews. 1963. The treatment of haemorrhage in von Willebrand's disease and the blood level of factor VIII (AHG). Br. J. Haematol. 9: 203214.

6. Cornu, P., M. J. Larrieu, J. Caen, and J. Bernard. 1963. Transfusion studies in von Willibrand's disease: effect on bleeding time and factor VIII. Br. J. Haematol. 9 : 189-202.

7. Shulman, N. R., D. H. Cowan, E. P. Libre, S. P. Watkins, Jr., and V. J. Marder. 1967. The physiologic basis for therapy of classic hemophilia (factor VIII de- ficiency) and related disorders. Ann. Intern. Med. 67: 856-882.

8. Barrow, E. M., H. R. Roberts, K. Pons, and J. B. Graham. 1964. Studies of the antihemophilic factor (AHF, factor VIII) produced in von Willebrand's disease. Proc. Soc. Exp. Biol. Med. 115: 760-763.

9. Bennett, B., O. D. Ratnoff, and J. Levin. 1972. Immunologic studies in von Willebrand's disease. Evidence that the antihemophilic factor (AHF) produced after transfusions lacks an antigen associated with normal AHF and the inactive material produced by patients with classic hemophilia. J. Clin. Invest. 51: 2597-2601.

10. Muntz, R. H., H. Ekert, and H. Helliger. 1974. Properties of post-infusion factor VIII in von Willebrand's disease. Thromb. Res. 5: 111-123.

11. Ahr, D. J., F. R. Rickles, L. W. Hoyer, D. S. O'Leary, and M. E. Conrad, von Willebrand's disease and hemorrhagic telangiectasia. Am. J. Med. In press.

12. Bloom, A. L., I. R. Peake, and J. C. Giddings. 1973. The presence and reactions of high and lower-molecularweight procoagulant factor VIII in the plasma of patients with von Willebrand's disease after treatment: significance for a structural hypothesis for Factor VIII. Thromb. Res. 3: 389-404.

13. Thomson, C. C. D. Forbes, and C. R. M. Prentice. 1973. Relationship of factor VIII to ristocetin-induced platelet aggregation: effect of heterologous and acquired factor VIII antibodies. Thromb. Res. 3: 363-372.

14. Ingram, G. I. C. 1961. Increase in antihemophilic globulin activity following infusion of adrenaline. J. Physiol. (Lond.). 156: 217-224.

15. Egeberg, O. 1964. Conditions associated with increased blood factor VIII activity. In The Hemophilias. K. M. Brinkhous, editor. The University of North Carolina Press, Chapel Hill, N. C. 203-213.

16. Egeberg, O. 1963. Changes in the activity of antihemophilic A factor (F. VIII) and in the bleeding time associated with muscular exercise adrenaline infusion. Scand. J. Clin. Lab. Invest. 15: 539-549.

17. Egeberg, O. 1963. The effect of muscular exercise on hemostasis in von Willebrand's disease. Scand. J. Clin. Lab. Invest. 15: 273-283.

18. Libre, E. P., D. H. Cowan, S. P. Watkins, Jr., and N. R. Shulman. 1968. Relationships between spleen, platelets and factor VIII levels. Blood. 31: 358-368.

19. Rizza, C. R., and J. Eipe. 1971. Exercise, factor VIII and the spleen. Br. J. Haematol. 20: 629-635.

20. Mannucci, P. M., G. Gagnatelli, and R. D'Alonzo. 1972. Stress and blood coagulation. Thromb. Diath. Haemorrh. 51 (Suppl.) : 105-113.

21. Prentice, C. R. M., C. D. Forbes, and S. M. Smith. 1972. Rise of factor VIII after exercise and adrenaline infusion, measured by immunological and biological techniques. Thromb. Res. 1 : 493-505.

22. Bennett, B., and O. D. Ratnoff. 1972. Changes in antihemophilic factor (AHF, factor VIII) procoagulant activity and AHF-like antigen in normal pregnancy, and following exercise and pneumoencephalography. J. Lab. Clin. Med. 80: 256-263.

23. Denson, K. W. E. 1973. The detection of factor-VIIIlike antigen in haemophilic carriers and in patients with raised levels of biologically active factor VIII. $\mathrm{Br}$. J. Haematol. 24 : 451-461.

24. Mannucci, P. M., M. Åberg, I. M. Nilsson, and B. Robertson. 1975. Mechanism of plasminogen activator and factor VIII increase after vasoactive drugs. $\mathrm{Br} . J$. Haematol. 30: 81-93. 
25. Green, A. J., and O. D. Ratnoff. 1974. Elevated antihemophilic factor (AHF, Factor VIII) procoagulant activity and AHF-like antigen in alcoholic cirrhosis of the liver. J. Lab. Clin. Med. 83: 189-197.

26. Holmberg, L., and I. M. Nilsson. 1974. AHF related protein in clinical praxis. Scand. J. Haematol. 12: 221231.

27. Proctor, R. R., and S. I. Rapaport. 1961. The partial thromboplastin time with kaolin. A simple screening test for first stage plasma clotting factor. Am. J. Clin. Pathol. 36: 212-219.

28. Rickles, F. R., J. A. Hardin, F. A. Pitlick, L. W. Hoyer, and M. E. Conrad. 1973. Tissue factor activity in lymphocyte cultures from normal individuals and patients with hemophilia A. J. Clin. Invest. 52: 1427-1434.

29. Hoyer, L. W. 1972. Immunologic studies of antihemophilic factor (AHF, factor VIII). Radioimmunoassay of AHF antigen. J. Lab. Clin. Med. 80: 822-833.

30. Mielke, C. H., Jr., M. M. Kaneshiro, I. A. Maher, J. M. Wiener, and S. I. Rapaport. 1969. The standardized normal Ivy bleeding time and its prolongation by aspirin. Blood. 34 : 204-215.

31. Breckenridge, R. T., and O. D. Ratnoff. 1962. Studies on the nature of the circulating anticoagulant directed against antihemophilic factor: with notes on an assay for antihemophilic factor. Blood. 20 : 137-149.

32. Rick, M. E., and L. W. Hoyer. 1973. Immunologic studies of antihemophilic factor (AHF, Factor VIII). V. Immunologic properties of AHF subunits produced by salt dissociation. Blood. $42: 737-747$.

33. Ratnoff, O. D., L. Kass, and P. D. Lang. 1969. Studies on the purification of antihemophilic factor (Factor VIII). II. Separation of partially purified antihemophilic factor by gel filtration of plasma. J. Clin. Invest. 48: 957-962.

34. Levin, J., and D. P. Jackson. 1968. Variable responsiveness in von Willebrand's disease. Int. Soc. Hematol., Proc. Congr. 7th, 177.

35. Meyer, D., M. J. Larrieu, P. Maroteaux, and J. B. Caen. 1967. Biological findings in von Willebrand pedigrees: implications for inheritance. J. Clin. Pathol. (Lond.). 20: 190-194.

36. Bowie, E. J. W., D. N. Fass, J. D. Olson, and C. A. Owen, Jr. 1974. Transfusion and autotransfusion of plasma in von Willebrand's disease. Thromb. Res. 5: 479-494.

37. Perkins, H. A. 1967. Correction of the hemostatic defects in von Willebrand's disease. Blood. 30: 375-380.
38. Hoyer, L. W., R. de los Santos, and J. R. Hoyer. 1973. Antihemophilic factor antigen. Localization in endothelial cells by immunofluorescent microscopy. J. Clin. Invest. 52: 2737-2744.

39. Bloom, A. L., J. C. Giddings, and C. J. Wilks. 1973. Factor VIII on the vascular intima: possible importance in haemostasis and thrombosis. Nat. New Biol. 241: 217-219.

40. Jaffe, E. A., L. W. Hoyer, and R. L. Nachman. 1973. Synthesis of antihemophilic factor antigen by cultured human endothelial cells. J. Clin. Invest. 52: 2757-2764.

41. Jaffe, E. A., L. W. Hoyer, and R. L. Nachman. 1974. Synthesis of von Willebrand factor by cultured human endothelial cells. Proc. Natl. Acad. Sci. U. S. A. 71: 1906-1909.

42. Holmberg, L., P. M. Mannucci, I. Turesson, Z. M. Ruggeri, and I. M. Nilsson. 1974. Factor VIII antigen in the vessel wall in von Willebrand's disease and haemophilia A. Scand. J. Haematol. 13: 33-38.

43. Weiss, H. J. 1974. Relation of von Willebrand factor to bleeding time. N. Engl. J. Med. 291: 420.

44. Ratnoff, O. D., and B. Bennett. 1973. Clues to the pathogenesis of bleeding in von Willebrand's disease. N. Engl. J. Med. 289 : 1182-1183.

45. Ratnoff, O. D., and H. Saito. 1974. Bleeding in von Willebrand's disease. N. Engl. J. Med. 290: 1089.

46. Ruggeri, Z. M., F. I. Pareti, P. Bintadish, and P. M. Mannucci. 1974. Clotting factors in von Willebrand's disease. Lancet. 2 : 105-106.

47. Weiss, H. J., and L. W. Hoyer. 1973. von Willebrand factor: dissociation from antihemophilic factor procoagulant activity. Science (Wash. D. C.). 182: 11491151.

48. Rapaport, S. I., S. Schiffman, M. J. Patch, and S. B. Ames. 1963. The importance of activation of antihemophilic globulin and proaccelerin by traces of thrombin in the generation of intrinsic prothrombinase activity. Blood. 21 : 221-235.

49. Özge-Anwar, A. H., G. E. Connell, and J. F. Mustard 1965. The activation of factor VIII by thrombin. Blood. 26: 500-509.

50. Weiss, H. J., and S. Kochwa. 1970. Molecular forms of antihaemophilic globulin in plasma, cryoprecipitate and after thrombin activation. Br. J. Haematol. 18: 89-100.

51. Cooper, H. A., F. F. Reisner, M. Hall, and R. H. Wagner. 1975. Effects of thrombin treatment on preparation of factor VIII and the $\mathrm{Ca}^{2+}$-dissociated small active fragment. J. Clin. Invest. 56: 751-760. 